\title{
LA FIGURA FEMENINA EN MEDEA. EURÍPIDES, SÉNECA Y ANOUILH
}

Cilly Müller de Inda

Dora Gladis Villalba de Boschetti

\section{INTRODUCCIÓN}

El mito de Medea nos ha permitido centrarnos en tres tragedias enraizadas en él. Dos de ellas corresponden al mundo clásico: Eurípides y Séneca; la restante, se ubica en el siglo $\mathrm{XX}$ : Anouilh.

Nos hemos ceñido exhaustivamente al texto más que al contexto, del cual ofrecemos sólo algunas coordenadas.

Nos interesó en forma especial el tratamiento de la psicología femenina de épocas de crisis como las que vivieron los tres dramaturgos aludidos. Remitimos pocas veces al texto original porque tuvimos en cuenta versos claves para la connotación del personaje.

\section{EURÍPIDES (480-406 a. C.)}

Jaeger pinta de manera magistral la época en que Eurípides desarrolló su actividad artística: "La sofística tiene una cabeza de Jano, una de cuyas caras es la de Sófocles y la otra la de Eurípides. El ideal del desarrollo armónico del alma humana es común a los sofistas y a Sófocles. Se halla relacionado con el principio escultórico de su arte. En la oscilante inseguridad de sus principios morales revela la educación sofística su parentesco con el mundo escindido y contradictorio que se manifiesta en la poesía de Eurípides." (JAEGER, W. Paideia; trad. J. Xirau y W. Roces. México, FCE, 1967, p. 303).

Consumada una de las grandes bancarrotas: "la de los dioses", al decir de Murray en La religión griega, se está gestando la corrosión de la segunda caída: la bancarrota de la $\pi \delta$ $\lambda \uparrow \zeta$, después del triunfo frente al bárbaro persa.

El escepticismo y el relativismo tiñen el espíritu griego. Perdida su fe, el hombre "es la medida de todas las cosas", como lo afirman los sofistas. Eurípides encarna fielmente el momento que le tocó vivir.

\section{SÉNECA (4-65 d.C.)}

Vivió todos los avatares de la dinastía Julio-Claudiana. La lenta descomposición del mundo romano luego de la muerte de Augusto, después de la que se suceden emperadores neuróticos, dementes, extravagantes y donde la penetración del cristianismo y el avance del bárbaro mostraron la fragilidad de un imperio otrora indestructible.

En esta multiplicidad, muchos romanos buscaron consuelo en las filosofias que tenian como ideal al hombre autosuficiente: el epicureismo y el estoicismo, doctrinas que conoció Séneca, adhiriendo especialmente a esta última, de la que dio testimonio hasta el momento de su muerte. Según Julián Marías, el tipo de vida que caracteriza a epicúreos y estoicos, esta 
definido por dos notas reveladoras de una humanidad cansada: suficiencia e imperturbabilidad; bastarse a sí misno y no alterarse por nada.

Séneca tuvo un triste fin a manos del último de los emperadores de la primera dinastía, el delirante Nerón, a quien había educado sin éxito. Como dice Lorenzo Riber: "La moral de Séneca, caída en el alma infame de Nerón, dejó en ella los reconcomios, las dudas, las claridades del propio conocimiento. Nerón no perdonó a Séneca que le hiciese comprenderse infame y poetastro".

"Séneca, y con él, Petronio, Lucano y Persio, que descubrieron, bajo una sacudida de la inteligencia cómo no había ya nada que esperar de esta época, llegaron a crear en el nuevo estilo, las obras que representan el barroco de la literatura latina, si se nos permite esta expresión de la historia de la cultura, y que a su vez, señalan al hombre una nueva posición en el mundo". (BUCHNER, Karl. Historia de la literatura latina; prol. Alfonso Ortega Carmona; trad. E. Valentí Fiol y A. Ortega Carmona. Barcelona, Labor, 1968, p. 326).

\section{ANOUILH (1910-1987)}

Vive la época de post-guerra. Un momento en el que el hombre está totalmente descreído y en busca de un nuevo orden para restablecer el equilibrio de un mundo que ya se ha perdido. Por eso es que se puede observar el choque entre las aspiraciones humanas y la realidad descarnada, despojada de toda poesía.

Nació en Burdeos en 1910. Según Lanson-Tuffrau, él mismo declara, que: "no tiene biografia". Hizo estudios de derecho y pasó dos años en una empresa de publicidad. Anouilh afirma que después del suceso de L'Hermine (1932) "sólo vivió para el teatro".

El Sigfrido de Giraudoux le revela su vocación; otras influencias fueron: Musset, Marivaux "releídos mil veces", Claudel, Pirandello, Shaw y evidentemente, Moliere.

Anouilh es francamente pesimista, "su obra se presenta como una rebelión contra todo lo que va en contra de la pureza de los seres" (LAGARDE, André y MICHARD, Laurent. XX Siecle. Les grands auteurs Français. Presses L.P.-F., 1965, t. VI, p. 569).

Obstinadamente vuelve siempre a un único problema: "la oposición entre el envilecimiento de la existencia y aquella aspiración a la pureza que no reclama ninguna trascendencia, quizá porque es, sencillamente, como se ha sugerido, la nostalgia de un retorno imposible al verde paraíso de los amores infantiles." (GAETAN PICON, Panorama de la literatura francesa actual; trad. Juan Gisch. Madrid, Guadarrama, 1958)

\section{MEDEA de Eurípides}

Dominante y majestuosa, la bárbara Medea es el eje de la obra. Todos los personajes tienen sus ojos puestos en ella.

Ya desde el prólogo, por boca de su vieja nodriza, sin haber tenido contacto con ella, tenemos el retrato de Medea:

- fugitiva de la Cólquide, por amor a Jasón, habita con sus hijos en Corinto, querida por los ciudadanos. 
- navegante de la Argos, ha tomado parte en el regreso de la expedición por el vellocino de oro.

- traiciona a su padre, asesina a su hermano y al anciano Pelias.

- esposa desdichada con suerte hostil: Jasón contrae nuevas nupcias con la hija del rey Creonte.

- herida, humillada "ignominiosamente en lo más sensible de su corazón, clama y jurá" (...) y pone a los dioses por testigos "de la ingratitud de su marido".

- "impasible como una piedra, yace sin tomar alimento".

- "llora a su padre amado, a su Patria y a sus palacios"

- odia a sus hijos y no se alegra al verlos.

- es de "carácter vehemente y no puede sufrir injurias"

- "Ningún adversario triunfará de ella con facilidad"

- "No oye los consejos de sus amigos"

Se agiganta su figura en la sentencia terrible de la anciana: "Yo la conozco y le temo".

Más adelante, el pedagogo dirá, preocupado porque no tenga contacto con los niños: "He visto el furor que expresaban sus ojos (...) Ojalá que la víctima sea algún enemigo, no un amigo".

Indudablemente, los dos servidores saben de lo que es capaz cuando la ira se posesiona de ella y están espantados.

Coincidente con ese retrato adelantado, Medea abre su corazón a las mujeres corintias y les expone sus dolores en un alegato feminista cabal y valiente: (p. 33)

- considera a la mujer como "la más desventurada de todos los seres que conocen y sienten "porque necesita comprar un esposo a costa de grandes riquezas y darle el señorío de su cuerpo, sin saber si dicho esposo será bueno o malo;

- no le es legítimo el divorcio;

- no puede repudiar al marido;

- la considera en inferioridad de situación para enfrentar una vida desconocida para ella, pues el hombre puede buscar solaz en casa de amigos y compañeros, pero la mujer sólo en ella misma tiene su esperanza;

- rebate a los que consideran que su vida en el hogar es placentera y libre de peligros;

- se ufana en decir que más quisiera "embrazar tres veces el escudo que parir una sola".

Creonte añade pinceladas maestras, llamándola "la de torva mirada, llena de ira contra tu esposo". Teme que dañe a su hija pues la sabe "(...) astuta, maestra en artificios (...) profieres amenazas (...) y no disimulas tu propósito de vengarte (...)"

Jasón la considera "insensata", pero de "sutil ingenio" "Mujer odiosa, mujer la más detestable de los dioses, de mí y de toda la especie humana; el más terrible azote; eres leona, no mujer, de índole más fiera que la tirrena Scyla".

Como mujer fuerte que es, segura de sí misma, le indigna la debilidad femenina que sólo reacciona cuando la afrenta que recibe afecta a su tálamo conyugal. Airosa, exclama con mucha valentía que, en ese caso: "No hay nadie más cruel" 
Astuta, calculadora, fría, obra como una serpiente: enroscada, cavila, "ni levanta sus ojos, ni los separa de la tierra (...)" pero urde una trama mortífera. Su mejor arma es su lengua. Envuelve con argumentos falaces e inteligentes para conseguir su objetivo. Conocedora de la naturaleza humana se aprovecha de las debilidades de sus adversarios para sacar provecho. Pronuncia sentencias razonables.

No cabe en ella la humildad. Piensa en sí misma antes que en los demás y se asegura un refugio antes de actuar. Todo lo planea.

Orgullosa, altiva, no puede aceptar el sufrimiento purificador (no se da en ella el esparagmós). Acostumbrada a obtener y gozar del botín, no se resigna a perder. Exacerbado su odio, toda ella es un volcán abrasador que invoca a los seres subterráneos y no vacila en emplear su magia y maleficios contra aquéllos que la traicionaron. El destierro la signa y ahonda su soledad.

Ha decidido matar a Creusa, a Creonte y a sus propios hijos para que el dolor de Jasón no tenga límites. Su marido habrá de soportar solo tamaña iniquidad: mucho más fácil habría sido privarlo de la vida pero su estilete es profundo y desea que él quede envuelto en sombras y llantos muy amargos. Ni siquiera tendrá el consuelo de enterrar a sus pequeños. A este respecto, Cantarella apunta: "Resulta extraña por cierto, en la Atenas escéptica y sofista de su tiempo, esta explosión de pasiones, este absurdo triunfo de lo irracional y del instinto que es la figura de Medea, en la que el poeta no se ha dejado intimidar ni siquiera por uno de los más firmes y convencionales lugares comunes, no ya de la literatura sólo sino del sentimiento general, el amor materno" (CANTARELLA, R. La literatura griega clásica; trad. A. Camarero. Losada, Bs. As., 1971).

Detengámonos, pues, en el parlamento que ella pronuncia con el pedagogo, instantes antes de que sus hijos lleven los regalos a la hija del rey. Su calidad de madre la domina inicialmente. Lo observamos en el vocativo que dirige a los niños ${ }^{\top} \Omega \tau \dot{\varepsilon} \kappa \nu \alpha, \tau \varepsilon \dot{\kappa} \boldsymbol{\alpha} \alpha$ (v. 1021), acentuando con la raíz $\tau \varepsilon \kappa-\tau 0 \kappa-\tau \kappa:$ producir, engendrar; que los niños se han nutrido de su ser y son, efectivamente, hijos de sus entrañas. Es tal vez éste uno de los pasajes en el que se perfila la humanidad de su figura.

La tierna mirada de sus hijos es capaz de derrumbarla. Esta mirada atenta e inocente está recalcada por la doble presencia de la raíz ó $\pi-\circ \varphi, \circ \psi, \circ \mu$ : ver, en ǒ $\mu \mu \alpha \sigma \imath v:$ mirada

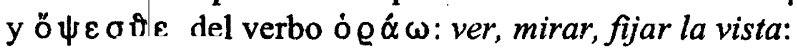

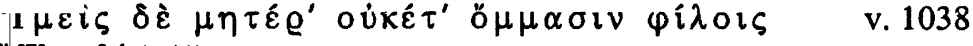

$$
\begin{aligned}
& \text { ठั } \Psi \varepsilon \sigma \theta^{\prime}(\text {...)" } 1039
\end{aligned}
$$

Pero se sobrepone y continúa con su proyecto escalofriante: su orgullo pisoteado es más fuerte que su amor de madre.

Monólogo íntimo que deja en claro su egoísmo: "Serviré yo de risa quedando impunes mis enemigos? Audacia!"

La asaltan dudas que retardan su accionar pero no ceja en su propósito.

Eurípides conoce la técnica del discurso y alterna períodos de tensión con otros de pasividad; corriendo velos que descubren nuevas facetas de Medea. El odio ha creado el clímax dramático. Implacable, Medea no cesa de razonar atinadamente. Claramente comprende la alevosa magnitud de su perfidia pero, implacable consigo misma, no puede volverse atrás. El texto original se abre con $\kappa \alpha i \quad \mu \alpha \nu \delta \hat{\alpha} \nu \omega<\mu \varepsilon \nu-\mu \nu \eta \mu \alpha \nu-\mu \alpha \nu \tau-\mu \alpha \nu \theta$ : 
actividad mental. El aspecto durativo del presente refleja la enajenación que la domina en el instante en que habla. El verbo $\tau \circ \lambda \mu \eta \tilde{\sigma} \omega$, en futuro indica la decisión irrefutable de la protagonista que habrá de consumar su propósito. To $\lambda \mu \alpha \hat{\alpha} \omega<\tau \lambda \hat{\eta} v \alpha \imath$, de la raiz $\tau \varepsilon \lambda$, $\tau 0 \lambda$, $\tau \alpha \lambda, \tau \lambda$ : soportar, tomar una carga, sufrir, tolerar; pero también osar, atreverse.

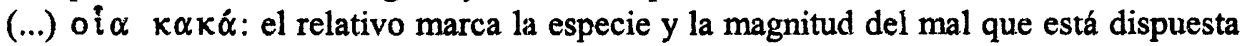

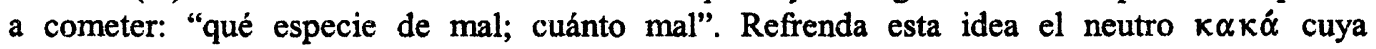
significación es: malo en todas las acepciones (sucio, feo, cobarde, malvado, innoble...)

El uso de $\theta \cup \mu o ́ s$ ubica la acción en el plano de la pasión descontrolada. La raíz ô $v$ contiene la idea de ebullición y la menos fuerte de arremolinamiento, como lo hace el humo. OUน⿰ó $\varsigma$ señala la ebullición interna de la cólera o del alma en actividad más bien que el "aliento vital" simbolizado a menudo en el "humo"producido por el aliento de la respiración. En latín, al contrario, sólo ha quedado en sentido material y éste, empobrecido: "fumus", en efecto el paralelo exacto de $\delta \cup \mu o ́ s$ (corresponde la $\theta$ inicial y la f), significa solamente humo.

El comparativo $\kappa \varrho \varepsilon i \sigma \sigma \omega \nu$ de la misma raíz de $\kappa \varrho \alpha ́\{0 \varsigma$ magnifica su pasión (más fuerte, más poderosa).

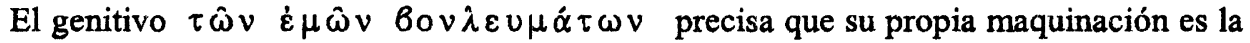
materia de su ira, como lo atestigua el uso del verbo $b \circ \cup \quad \lambda \circ \mu \alpha$ i: querer imponer su voluntad.

Se nota claramente que el poeta subraya que el proyecto nació en la mente

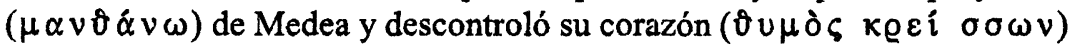

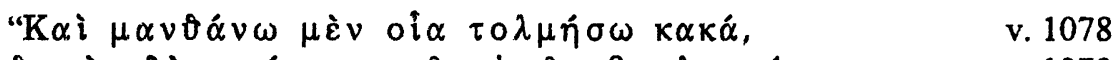

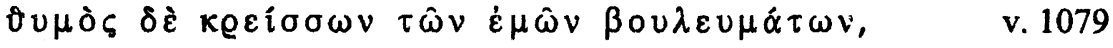

Consumada la matanza, Medea irrumpe ufana del dolor que ha causado a su marido. Su triunfo de mujer se ha perpetrado. Acabada la venganza, sólo le interesa huir hacia el palacio de Egeo. Más que nunca, se encierra en sí misma.

El coro alivia las tensiones: "mucho nos sorprende la actitud de los dioses y sus designios insondables para el mortal".

\section{MEDEA de Séneca}

Desde un principio, Medea, que abre la obra, está resuelta a consumar una venganza cruenta y desmesurada: "Ahora asistidme, ahora, diosas del crimen vengadoras, soltad la greña de serpientes flacas, blandiendo la negra hacha en las sangrientas manos; sedme presentes como otrora me lo fuisteis cuando en mi boda horribles os mostrasteis: dad la muerte a su esposa nueva, la muerte a su suegro y a su estirpe regia; (...)"

Llena de odio contra su marido, a quien desea ver destruido: “(...) inspiradme a mi un mal para imprecarlo contra mi marido; que viva, que vague mendigo por ignotas urbes, desterrado, espantado, aborrecido, sin lar cierto; (...)"

Quiere actualizar sus maquinaciones: "Quejas y palabras siembro en vano. No arremeteré contra los enemigos?"

Considera que después de la experiencia de la maternidad, puede llevar a cabo crímenes que superen en horror a los anteriores: "(...) crimenes mayores parecen bien en mí, después de que he sido madre". 
Su decisión es indubitable: "Rompe ya tu cobarde titubeo. La mansión que con un crimen granjeaste, con otro crimen la has de abandonar".

El fuego, que en su maquinación obrará en su papel protagónico, oficia calladamente de servil agente de Medea. Tiene vida por sí mismo y es capaz de asociarse a los designios de la hechicera. Interpreta su odio maléfico. El coro anticipa su vigencia: "Que el fescenino mordedor esparza sus festivos dicterios; suelte la turba sus fuegos; (...)"

Medea declara que su muerte espiritual la causó el canto nupcial y se deleita en consideraciones acerca del proceder de su esposo que la menoscaba y la cree débil: "Hizo desdén de mis merecimientos él, que me había visto vencer por maldad el mar y el incendio! Hasta tal punto cree agotada toda mi malignidad?"

Con crueldad defiende su amor desenfrenado: "Incierta, desatinada, a todas partes me lleva mi delirio furioso: (...)".

Duramente ataca a Creón y lo considera autor de sus desventuras. Está decidida a exterminar su casa con un castigo ejemplar: "colmaré su casa de ceniza: y el humo negro que salga de las llamas habrá de verlo el cabo de Malea, que a tan largos rodeos obliga a los navios".

Se jacta de ser quien es y de concentrar en sí toda la maldad: "Queda Medea; y con ella, el mar y la tierra, $y$ el hierro y el fuego, y los dioses y los rayos".

Creón conoce su perversidad y de no haber sido por los ruegos de Jasón, hubiera terminado con "esa pésima infección", "horrendo monstruo"

Altiva, acostumbrada a no doblegarse, el rey desea imponerle su poder autoritariamente. Ladinamente, lo envuelve con halagos para conseguir que retrase la orden de su destierro. Sólo aquí no duda en volverse indefensa y saca a relucir su maternidad: "Por el augurio feliz de este himeneo; por sus venideras esperanzas, por el estado de los reinos que voluble la fortuna asenderea en vicisitudes varias, suplícote: da una breve tregua a la fugitiva, mientras, quién sabe si moribunda ya, imprimo intensamente en mis hijos los besos postrimerus".

La vieja nodriza, espantada, comprende la locura de su ama y teme: "Bien así como la Ménade, cuando ya presa del dios, delira y loca de furor sagrado lleva sus pasos por la cumbre del nevoso Pindo o por los picos del Nisa, tal ella discurre en desatinado curso, llevando en su visaje todos los síntomas de la locura furiosa. La faz fogosa, precipitado el huelgo, lanza alaridos, riega sus ojos de copiosos llantos; serénase luego; de toda pasión da muestras. Hesita, amenaza, se enfebrece, se queja, gime. Adónde se inclina el peso de su alma? Dónde descargará sus amenazas? En qué rompiente quebrará este oleaje? Su furor rebosa; no es leve, no, ni es vulgar el crimen que medita; se superará a si misma; conozco las señales de su enojo. Algo grande amenaza, algo descomedido, salvaje, impio; veo su cara de furor. Engañe el cielo mis temores!"

Tremendamente egoísta, piensa que, llevada a cabo su acción reivindicatoria, nada más tendrá sentido: "Pues yo me voy, váyase todo"

Considera que su venganza será imperecedera y que servirá de escarmiento tanto para hombres como para dioses: "Haré este día, sí, este día haré una hazaña que jamás por jamás habrá que callar el tiempo: arremeteré contra los dioses y todo lo trastornaré".

Jasón se presenta sumiso ante ella, dispuesto a suavizarla: "Mi alma se decidió a desarmar su ira con mis ruegos. Y hela aqui; mi presencia la hizo rebotar; la exaspera; respira odios; su rencor está en su cara.". Pero debe enfrentarse con su ira y sus recriminaciones. Le 
ofrece que huya con ella pero él teme la venganza de los poderosos: "Mientras puedas partir, huye, desaparece de aqui; grave es siempre la ira de los reyes". Ella le recuerda: "Existe algo más terrible: Medea".

Es padre por encima de todo y Medea se aprovecha de su sentimiento. Encuentra allí la veta por donde habrá de asestar el golpe: "Así ama a sus hijos? Está bien: ya le tengo: descubrí el lugar para la herida"

La nodriza espeluzna con un patético monólogo en el que da cuentas de cuáles son, cabalmente, los poderes maléficos de Medea: toca el ara con la mano izquierda e invoca a venenos y monstruos; exprime hierbas mortales y aves agoreras. Atrae reptiles, prorrumpe conjuros.

La misma Medea se extasía largamente en convocar a las sombras, los dioses fúnebres, a Caos, la Luna siniestra. Hace gala de sus bienes: el fuego que Prometeo le diera y el de Vulcano, inextinguible y cubierto de tenue azufre; los dones de la Quimera; las llamas que expedían las fauces del Toro y la hiel de la Medusa. Invoca a Hécate para que el ardor del fuego, que todo lo destruye, perviva en los regalos que hará a Creusa y consuma implacable, a ella, a su padre y al palacio todo.

Perpetrado el crimen de la novia y su padre, escuchamos a Medea que, en diálogo con su nodriza, se niega a abandonar el país de los Pelópidas; el parlamente comienza así:

Egone ut recedam? (v. 893) La primera persona remarca su indeclinable decisión de quedarse con el reforzativo -ne.

Considera que la venganza es insuficiente; y utiliza el término "ultionis" (v. 896) cuya raíz es la misma de "Ulciscor" que significa "castigar a uno por una injuria cometida". Y se apresta a realizar algo mucho más grande: "Qué pequeña es esa parte de venganza de que gozas! (...) harto chica es la venganza que deja blancas las manos".

En el verso 897 se pregunta a sí misma: "Amas adhuc, furiosa ..." el verbo "Amo" (hacer el amor) especifica el sentimiento femenino relacionado con el plano erótico (a diferencia de diligo: estimar, distinguir, amar con afecto fundado en la elección y reflexión; y velle < volo: querer, decidir, demandar, en el que la voluntad juega un papel preponderante).

Medea aún siente en sí la desmesura de sus sentimientos que se ve subrayada por el adjetivo "furiosa"; cuyo tema básico se relaciona con el verbo furo, el que a su vez está emparentado con el griego ố $u$, que habla del bullir de la pasión. El vocativo transmite la idea de "agitado por la furia, delirante, extraviado, arrebatado y demente".

Poco más abajo, vuelve a referirse a la venganza, pero esta vez, bajo la forma de "vindicta" (v.901), de la misma familia del verbo uindico y de uindex, que semánticamente apuntan a designar al que toma a su cargo una cuestión y sus consecuencias, al que sale responsable de algo. Medea se proclama autora de su propia reivindicación y defensa.

Se envanece de sus asesinatos anteriores y los considera ínfimos comparados con los que se siente capaz de hacer: "A todo cuanto perpetraste hasta aqui, dale el nombre de piedad. (...) Ahora soy Medea; creció mi ingenio en el mal. (...) Busca materia, oh despecho mio! No será inhábil la mano que llevares a cualquier gesta de maldad". reaparece."

Decide matar a sus hijos y entra en conflicto: "(...) y expulsada la esposa, la madre

"Egone ut morum liberum ac prolis meea/ fundam cruorem? (vv. 929-30). El sustantivo cruorem en relación con el sánscrito kravya: carne viva y krûra: sangriento, llaga; 
nos remite a la "sangre derramada, charco de sangre, sangre roja", es decir: la sangre palpitante de quien recién ha perdido su soplo vital. Por oposición a sanguis: sangre que se encuentra en la circulación. Distinción observada por buenos autores, cfr. Lucrecio. Atestiguada a partir de Varrón en toda la latinidad.

Es interesante, además, remarcar la gradación en las ideas de : "crimen" y "morir":

"(...) Melius, a demens furor,/ incognitum istud facinus ac dirum nefas/ a me quoque absit; quod scelus miseri lueht?" (vv. 930-31-32). En el primer caso, aparece en primer lugar Facinus< facio: acto, acción, hecho en general, que generalmente, se toma en mala parte: fechoria, crimen, delito, acción culpable. Después, para referirse a la misma acción,

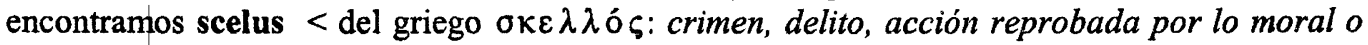
la religión.

Es evidente que Medea va procesando la magnitud de su acto filicida.

En el caso del verbo "morir" leemos en los versos 935-36:

"(...) occidant, non sunt mei;/ pereant, mei sunt (...)". Occido < ob cado; literalmente, "hacia la caida" y, por lo tanto, caer, sucumbir, perecer, morir; contrasta con pereo< per eo; pasar por, irse del todo, desaparecer, ser destruido, aniquilado. El preverbio per lleva la idea de "pasar de parte a parte, atravesar". Como en el caso del sustantivo, el poeta ha elaborado gradualmente la idea verbal en boca de la protagonista y ha jugado hábilmente en el plano semántico.

No duda frente a las opiniones que descubre: de todas maneras habrá de perder sus hijos y entonces, prefiere que terminen en sus manos y que sirvan para lavar sus crímenes familiares y para destruir a Jasón: "Perezcan para el padre; para la madre perecieron. (...) Horra he sido para mi venganza, sólo dos hijos yo pari; ya bastan por mi hermano y mi padre."

Siente que recobra su identidad: se reconoce como era antes de conocer a Jasón:

"Desde este momento recobré mi cetro. Colcos vuelve a tener mi hermano, a mi padre, y el vellocino del Carnero de oro; volvió mi patria; la virginidad que me robaste ha vuelto".

Comprende que todos sus crímenes anteriores no significaron nada, porque no tuvieron a Jasón como espectador: "Un placer grande a mi pesar me invade, y he aqui que va creciendo. Sólo me faltaba tenerte por espectador. Pienso que no es nada lo que ya he hecho; todos mis crimenes sin ese testigo fueron pura pérdida."

Jasón se ofrece a cambio de la vida de sus hijos, pero ella lo rehúsa porque su cometido es verlo destruido moralmente:

JASON (a Medea)

"Por todas las divinidades, por nuestra común fuga, por nuestro tálamo que mi fe no volvió, perdona ya a mi hijo. Si hay un crimen es mío; entrégome a la muerte, inmola mi cabeza culpable."

MEDEA

"Donde tú rehusas, donde tú te dueles, alli hundiré mi hierro. Vete ahora, hombre soberbio; busca lechos de virgenes; abandona a las que hiciste madres!"

El intenta persuadirla: "Una muerte sola basta a mi castigo" 
Desatada su soberbia, no puede controlar su $\check{u} \beta \varrho \imath \varsigma$ y si pudiera matar a alguien más de sus entrañas, lo haría con gusto: "Aun matando a dos será ese número harto exiguo para mi despecho. Y si alguna prenda de nuestro amor ocúltase en la madre, aun ahora, con la espada escudriñaré mi vientre sacaréle en la punta de la espada".

Pasivamente, Jasón ruega en un clima "in crescendo" que ejecute cuanto antes su plan: "Acaba ya la comenzada hazaña; nada te ruego más; perdona a mi suplicio al menos la crueldad de la tardanza".

Ella se deleita morosamente; "lento scelere" (v. 1016) con la muerte. Ha llegado la hora de Medea. Proclama su señorío frente a todos: "Meus dies est" (v. 1017).

Finalmente, Jasón, horrorizado le implora la muerte. Ella, altiva, le echa los cadáveres de sus hijos y huye en su carro alado. Jasón sólo atina a exclamar: "Vuela, sí; vuela por los espacios altos del cielo superior y atestigua que no hay dioses por donde tú te elevas!"

\section{MEDEA de Anouilh}

El dramaturgo francés tiene en cuenta, para elaborar el personaje, tres factores:

1) la sexualidad femenina que ha sido burlada;

2) las comparaciones con elementos del reino animal, en boca de la nodriza y de la propia Medea;

3) la inclusión de elementos cotidianos para desmitificar al personaje.

Conocemos a Medea a través del diálogo con su nodriza.

1) El sonido de la fiesta despierta recuerdos en las dos mujeres. La rememoración va preparando un clima de sensualidad: "La nodriza. - (...) Los mozos se pintan la cara de rojo con sus sangre, y a la madrugada, después de los primeros sacrificios, empiezan los combates. (...)

Y a la noche encendían grandes hogueras delante del palacio de tu padre, grandes hogueras amarillas con hierbas que olían fuerte (...)

(...) tú elegías, tranquila, desnuda, mientras te frotaban con aceite."

"Medea. - (...) Qué felicidad que hiede hasta aquí a sudor, a vino espeso, a frituras?"

Ella reconoce que por amor a Jasón ha robado a su padre y matado a su hermano.

Sugestivamente utiliza la primera persona: "(...) porque yo amaba a Jasón, (...)". No nos da datos que nos indiquen que el amor era recíproco.

Este clima de sensualidad alcanza su culminación cuando ella dice: "Qué cosa tan alegre pasa esta noche que a mi me aprieta, me ahoga?...Nodriza, nodriza, esta noche estoy encinta (...) Todavía tengo algo que echar al mundo esta noche, algo más grande, más viviente que yo y no sé si seré bastante fuerte..."

Su motivación reside en el hecho de su sexualidad avasallada por Jasón, después de haberla hecho mujer. Por eso, su odio se gesta en su matriz. En ningún momento ella alude a sentimientos espirituales. Su femineidad, que entregó por amor, nutrirá su ansia de venganza: "Mi hijo ha llegado solo. Y esta vez es un niño. Odio mío! Qué joven eres... Qué suave, qué bien hueles. Niñito negro, eres mi único cariño en el mundo"

Lamenta ser mujer porque ésta alcanza la plenitud pero también la destrucción a través del sexo: "Amputada!... Oh sol, si es cierto que vengo de ti, por qué me has hecho amputada? 
Por qué me has hecho mujer? (...) Mujer! Mujer! Perra! Carne hecha de un poco de barro y de una costilla de hombre. Trozo de hombre! Puta!"

Roto el vínculo que la une a Jasón, Medea se reconstituye, vuelve a ser quien era antes de enamorarse de él: "Me recupero. He soñado? Soy yo. Medea" A su vez, al perder la unidad con el otro, muere internamente: "Me muero. Suavemente lo mato todo en mi. Estrangulo"

Se teme a sí misma; sabe que no tiene límites en su afán vengador.

Muerta la esposa, renace con toda potencia la hechicera bárbara: "Yo también tengo miedo, pero no de su música, de sus gritos, de su rey piojoso, de sus órdenes; De mí! Jasón, tú la habias dormido y ahora Medea despierta! Odio! Odio! Gran ola bienhechora, me lavas y renazco"

2) Para subrayar la femineidad burlada y la potencia de la sexualidad aparecen alusiones al reino animal referidas a la protagonista:

La nodriza manifiesta:

"No lo esperes más, gatita mía. Te consumes"

"Mi águila orgullosa, mi pequeño buitre".

"Te vengarás, mi loba. Te vengarás, mi buitre"

La propia Medea se dice:

"Mujer, mujer. Perra"

Todas las imágenes se relacionan con la concupiscencia y la rapiña.

3) El autor intenta incluir el personaje mítico en el mundo secular, a través de la inserción de elementos cotidianos:

- La primera acotación de Anouilh; lo corrobora: "Medea y la nodriza, en cuclillas, delante de un carromato." Están lejos de la ciudad; no alcanzan a divisar la fiesta; tan sólo oyen la música y los festejos:

"La nodriza. - (...) ahora estamos aquí, en cuclillas, como dos mendigas, delante de este fuego que se apaga siempre.

Medea. -Ve a buscar leña." (...)

"Medea. - (...) Tenían miedo de que les robáramos las gallinas por la noche. (...)

(...)

Qué felicidad que hiede hasta aquí a sudor, a vino espeso, a frituras?"

- La vieja nodriza, apegada a los pequeños halagos de la vida de un pobre: "Medea, soy vieja, no quiero morir! Te he seguido, lo he dejado todo por ti. Pero la tierra todavía está llena de cosas buenas: el sol, en el banco al hacer alto, la sopa caliente a mediodía, en la mano las moneditas ganadas, el traguito que calienta el corazón antes de dormir."

- La promiscuidad en la que conviven: "La nodriza. - (...) Todo se sabe cuando se vive amontonados en un carromato."

Ya frente a Creón, Medea recobra la majestad de su abolengo real, de que deliberadamente. la ha privado Anouilh: "Soy Medea. La hija de Eates, (...) " Trata al rey con 
altivez y no le teme: "Soy de tu raza. De la raza de los que juzgan y deciden, sin volverse atrás y sin remordimientos. "Se considera superior a él: "Tú no procedes como rey, Creón".

Astuta y oportunista, no le duele achicarse y volverse indefensa para aprovecharse de la situación: "Qué hice yo a las gentes de Corinto? Robé sus corrales? Están enfermos los animales? Envenené las fuentes cuando fui en busca de agua para la comida?"

Es un gallo de riña que mide a su adversario. Cuando está segura de cuáles son las escasas fuerzas de su contrincante, muestra su verdadero porte sin piedad. Pues descuenta su triunfo. Reclama la posesión de Jasón con altivez, como si se tratara de un objeto material que le pertenece: "Sea, regreso. Ya no aterraré a las matronas de tu aldea, mi caballo tampoco volverá a robar la hierba escasa de tu páramo. Regreso a Colcos, pero aquél que me trajo, me lleve." (...) "Devuélveme a Jasón".

Hipócrita y sarcástica no puede dejar de traslucir su indignación frente a las nupcias que celebran con júbilo los corintios: "Qué diablos hace en tu aldea? A qué vienen esos disparos al aire, esos bailes, ese reparto de vino? (...) Invitame a mi también a la boda. Preséntame a tu hija. Puedo serle útil, sabes?. Hace diez años que soy la mujer de Jasón, tengo mucho que enseñarle a ella que lo conoce desde hace sólo diez días"

La debilidad de Creón la exaspera y ella se solaza en menoscabarlo en su ser viril:

"Creón, eres viejo. Hace mucho que eres rey. Has visto muchos hombres y muchos esclavos. Has hecho mucha cocina innoble.

(...)

Entonces eres demasiado viejo para ser rey! Pon a tu hijo en tu lugar, que haga el trabajo como es debido, y tú, vete a cuidar tus viñas al sol. Ya no sirves más que para eso! (...)

Has perdido las garras, viejo león (...)"

Él no es capaz de enfrentarla y baja la cabeza ante ella. Es el triunfo de Medea que se sabe dominadora de la situación. Estamos frente a una mujer dura, áspera, que ha sufrido vejámenes y que ha perdido todo por un amor que la traiciona. Burlada y mísera, no cree en nada superior: lo único que cuenta son sus propias fuerzas y rechaza con asco a quien se aferra a lo cotidiano:

"Cuenta con Medea! Hay que ayudar un poco al destino! Has perdido las garras, viejo león, si te convencen los ruegos, si quieres rescatar niños muertos (...) Bebe calditos, toma polvos y no te enternezcas contigo mismo, tan bueno el viejo Creón a quien conoces tan bien, un buen hombre, en el fondo, un incomprendido, pero de que todos modos degolló su buena ración de inocentes cuando aún tenia dientes y miembros sólidos"

En Medea, el ser es un "deber ser". No admite concesiones. Por ello, Creón pagará cara su debilidad de no empuñar el cetro como se debe: " $Y$ ya que tu sangre enfriada, tus glándulas muertas te han hecho bastante cobarde para concederme esta noche, vas a pagarla!"

En el diálogo con Jasón, Medea se enternece rememorando los momentos vividos con éi: "Vuelvo a verte de pie, como ahora, delante de mí, la primera noche de Cólquide. Aquel héroe moreno que bajaba de su barca, aquel niño mimado que quería el vellocino de oro y que no debia morir, eras tú, te parece?"

El amor ha dejado hondas huellas en los dos y juntos, organizaron un mundo a su medida. La unión carnal los ha marcado; las fechorías compartidas los volvieron cómplices y Medea sabe que Jasón no podrá olvidarla jamás, mientras viva: "Nunca te liberarás, Jasón! 
Medea será siempre tu mujer" Puedes ordenar mi exilio, mi extrangulación dentro de un instante cuando ya no puedas oirme gritar; nunca, nunca saldrá Medea de tu memoria (...)

Córtate las manos, Jasón, córtate las manos enseguida! Cambia de manos si quieres amar todavia. (...)

Para ti el mundo es Medea, por siempre".

Jasón, en contacto con las perversidades de Medea, aprendió a odiar el amor y desea casarse para encontrar un mundo nuevo donde reine la tranquilidad y la estabilidad: "Quiero el olvido y la paz" "No sólo te odio a ti: odio al amor"

Enredados en la misma telaraña, se debaten sin salida: se echan en cara mutuas infidelidades agrediéndose con dureza.

Jasón carece de coraje para llegar a la acción y no encuentra nada mejor que el desprecio para menoscabarla. La humilla compadeciéndose de su triste condición. Ha llegado a conocerla íntimamente y sabiendo que no cambiará ni siquiera desea comprometerse con su muerte.

Anouilh pone en boca de Jasón un parlamento en el que resaltan algunos conceptos que forman parte de su perspectiva vital:

- la persona se realiza imperativamente;

- el destino es irreversible;

- todo conflicto aparentemente irresoluble tiene desenlace desconocido por el hombre;

- cada hombre tiene un papel que cumplir;

- el hombre es limitado: alguien dispone con mayor poder;

- la aceptación de la verdad produce alivio de tensiones;

- la vida del hombre es un sinfín de situaciones dolorosas.

Estamos delante de un ser que ha evolucionado adecuándose a las circunstancias. Puede rememorar su vida con objetividad fría, pues ha roto con Medea. Esta ruptura le ha dado un cambio de óptica: es el hombre que acepta la realidad por comodidad; ha decidido no luchar más: "(...) Pegado a ese muro irrisorio construido por mis manos entre la nada absurda y yo"

Medea no puede entender su conformismo y se lo echa en cara: "Raza de Abel, raza de los justos, raza de los ricos, con qué tranquilidad habláis"

Ella se rebela contra el orden establecido: "(...) tener el cielo de parte de uno y también la policía"

Ante la irrevocable decisión de Jasón, la ruptura es un hecho y en la soledad, la angustia se apodera de Medea. En su desvarío daría cualquier cosa por retenerlo pero, súbitamente, se recompone y vuelve a dorninarla el odio: su plan debe llegar a término, en el plazo más breve posible: "Ya no tengo tiempo para escucharte. Ahora todo debe marchar terriblemente rápido"

La madre y la esposa se han perdido para siempre: ha vuelto a ser dueña de sí misma. Retoma este concepto imperativo "Medea: tienes que ser tú misma" en el magnífico monólogo que a modo de excelente monodia lírica Anouilh pone en boca de la hechicera Medea. El canto es un conjuro de amor erótico a su odio diabólico, lo único que le queda.

El tiempo se ha detenido en el mal lento, con perspectiva visceral. Un aliento sensual lo invade todo y la protagonista, en éxtasis carnal, se satisface plenamente con su embrujo maléfico al aue personifica y dota de virilidad: "Oh, mal! Gran bestia viviente que trepa por mi 
y me lame, tómame. Soy tuya esta noche, soy tu mujer. Penétrame, desgárrame, hínchate, y arde en medio de mi. Ya ves, te acojo, te ayudo, me abro... Pesa sobre mi con tu gran cuerpo velludo, apriétame con tus grandes manos callosas, con tu aliento ronco sobre mi boca, ahógame. Vivo por fin! Sufro y nazco. Son mis bodas! Por esta noche de amor contigo he vivido."

Esta cópula monstruosa la dota de una nueva percepción, por eso advierte todas las fuerzas subterráneas que están en juego esa noche:

" $Y$ tú, noche, noche pesada, noche rumorosa de gritos ahogados y de luchas, noche en que bullen los saltos de todas las bestias que se persiguen, se aman, se matan, aguarda un poco, por favor, no pases demasiado rápido..."

En esta nueva visión comienza a bestializarse: "Oh bestias innumerables a mi alrededor, trabajadoras oscuras de este páramo, inocencias terribles, mortíferas... Esto es lo que los hombres llaman una noche tranquila, este gigantesco hormigueo de cópulas silenciosas $y$ de crimenes. Pero yo os siento, yo os oigo a todas esta noche por primera vez, en el fondo de las aguas y de las hierbas, en los árboles, bajo la tierra... Una misma sangre late en nuestras venas. Bestias de la noche, estranguladoras, hermanas mias! Medea es una bestia como vosotras! (...) Bestias, soy vosotras! Todo lo que esta noche persigue y mata es Medea!"

El clímax está logrado: Medea ya no duda en llegar hasta el final: "Huir yo? Si ya me hubiera marchado, volvería para gozar del espectáculo.'

Enloquecida, recibe a sus hijos mientras los acaricia observa detenidamente dónde asestará el golpe mortal. Y con frialdad absoluta anuncia su propósito. "Ah, estáis aquí los dos? Tenéis miedo? (...) (estira las cabezas hacia atrás, mira sus ojos y murmura) Inocencias!

Trampa de los ojos de niño, bestezuelas solapadas, cabezas de hombre. Teneis frio? No os haré daño. Seré rápida" Intenta tranquilizar a los pequeños: "Sólo el tiempo para el asombro de la muerte en vuestros ojos (los acaricia)"

Invoca inútilmente a Jasón, conciente de que ésta es la última vez que su familia estará reunida: "Jasón! Aquí está tu familia, tiernamente unida. Mírala."

Se desdobla en la Medea que hubiera podido ser y la que es: "Yo hubiera querido, Jasón, tal vez hubiera querido yo también que esto durara siempre y que fuera como en las historias! Quiero, quiero aun en este instante, con tanta fuerza como cuando era pequeña, que todo sea luz y bondad!"

Nuevamente se desdobla: "Pero Medea inocente ha sido elegida para ser la presa y el lugar de la lucha(...) No todos los dias tienen los dioses esta ganga: un alma bastante fuerte para sus refriegas, para sus puercos juegos."

Fianalmente retoma el Yo y consuma su objetivo: "Aún tengo inocencia que degollar en esta chiquilla que tanto hubiera amado y en estos dos trocitos tibios (...) Entramos los tres en casa..."

Con alegría demente proclama su triunfo y su destrucción física: "Han muerto, Jasón! Han muerto degollados los dos, y antes de que puedas dar un paso, con el mismo hierro me mataré. He recuperado mi cetro; mi hermano, mi padre y el vellocino de oro que han sido devueltos a Cólquide: he recobrado mi patria, la virginidad que me habias arrebatado! Soy Medea, en fin, para siempre! (...)"

El último parlamento de Jasón es una alusión evidente a la postura pesimista del hombre de post-guerra, descreído, sin fe, apático, sin fuerzas, en busca de algún orden que restablezca la armonía perdida, aún a costa de sacrificar los sueños. La única certeza del hombre 
es esperar la muerte y observar el paso del tiempo, tratando de no salir de un orden rutinario y no rebelarse.

\section{CONCLUSIONES}

Abordamos tres textos referidos a un mismo mito. Los tres autores han recreado la figura de Medea, pero su postura frente a la praxis ha sido diferente. Quizá ello se deba a lo que Luis Gil engloba con el nombre de "toma de postura del autor recreador".

En este sentido, considera que los diferentes actos de esta toma de postura son: integración, proyección y enfrentamiento.

Si tomamos como hipotexto la tragedia de Eurípides y la confrontamos con las obras de Séneca y Anouilh observaremos que en estos dos últimos se produce la incorporación de todos los aspectos del mito, presentes en el texto de base.

Tanto en el caso de Séneca como en el de Anouilh no se presenta la imitación servil pues en la mímesis el autor latino revaloriza elementos del mito, como la dignidad femenina de la protagonista y su intento de reconstruir un cosmos que ha perdido.

Por otra parte, en Anouilh, las criaturas del mito encarnan, a través de lo anecdótico, los postulados del existencialismo, fundamentalmente, el enfrentamiento entre la libertad y el orden establecido.

Con respecto a la proyección, se mantiene el tiempo y el espacio en que transcurre la acción pero, la carga semántica de los parlamentos permite descubrir lo que Luis Gil denomina "sistema de coordenadas axiológicas, propias de una época dada" (pag. 17)

Finalmente, al considerar el enfrentamiento, se hace necesario remarcar la postura crítica del recreador inmerso en el contexto de su propia época. En el caso de Séneca, el mundo de la primera etapa del imperio romano con sus luchas de poder, sus violentos enfrentamientos familiares y su deterioro manifiesto. En el de Anouilh, la visión desesperanzada del hombre europeo, después de una guerra devastadora. 


\section{BIBLIOGRAFÍA}

ANOUILH, J. Teatro. Nuevas piezas negras. Traduc. A. Bernárdez. Losada; Bs. As, 1956.

BIGNONE, E. Historia de la literatura latina. Traduc. G. Halperín. Losada; Bs.As, 1952.

BUCHNER, K. Historia de la literatura latina. Traduc. E. Valentié Fiol y A. Ortega Carmona. Labor; Barcelona, s/fecha.

CANTARELLA,R. La literuatura griega clásica. Traduc. A. Camarero. Losada; Bs.As., 1971.

CHANTRAINE, P. Dictionnaire étymologique de la langue grecque Klincksieck; Paris, 1968/74/77.

ERNOUT, A. et MEILLET A. Dictionnaire étymologique de la langue latine. Histoire des mots. $4^{\circ}$ édition. Klincksieck, 1959.

ETEROVIC, MIRKO Lexicón.Diccionario de raíces. Prof. Salesiano "Miguel Rúa"; Córdoba, Argentina, 1970.

EURIPIDE Tome I. Le Cyclope, Alceste, Médée, Les Héraclides. Texte établi et traduit par L. Méridier. $6^{\circ}$ tirage. Société d'édition "Les Belles Lettres"; Paris, 1965.

EURÍPIDES Obras dramáticas. Traduc. E. Meir y Barbery. Revidada y corregida por C.A. Disandro. El Ateneo; Bs.As., 1966.

EURÍPIDES Medea. Estudio, versión y notas de María Celina Grifero. Edit. Columba; Bs. As., 1972.

FONTOYNONT, V. Vocabulario Griego. Adaptac. Española L. Ribot Armendia, S.J. $3^{a}$ edic. Sal Terrae; Santander, 1962.

GAETÁN PICÓN Panorama de la Literatura francesa actual. $2^{\mathrm{a}}$ edic. Guadarrama, Madrid, 1958.

GIL, LUIS Transmisión mítica. Planeta; Barcelona, 1975.

LAGARDE, A. et MICHARD,L. XX' Siècle, avec la collaboration de R. Audibert, H. Lemaitre et T. Van der Elst. T. VI, Bordas; France,1957.

MENDIZÁBAL, R. Diccionario mnemónico en Diccionario griego-español ilustrado. $5^{\mathrm{a}}$ edic. Razón y fe; Madrid, 1963.

MURRAY, GILBERT La religión griega. Traduc. Santiago Ferrari y Víctor D. Bouilly, s/fecha.

MURRAY, GILBERT Eurípides y su tiempo. Traduc. Alfonso Reyes. F.C.E.; México, 1978.

SÉNECA, L.A. Tragedias completas. Traducción, argumentos y notas de L. Riber Crisol; Madrid, 1961.

SENEQUE, L.A. Tagédies. Tome I. Texte établi et traduit par L. Herrmann. $3^{\circ}$ tirage. Société d"edition "Les Belles Lettres"; Paris, 1964. 